Supplement of Clim. Past, 15, 1557-1579, 2019

https://doi.org/10.5194/cp-15-1557-2019-supplement

(C) Author(s) 2019. This work is distributed under

the Creative Commons Attribution 4.0 License.

(c) (i)

Supplement of

\title{
Evaluating model outputs using integrated global speleothem records of climate change since the last glacial
}

\section{Laia Comas-Bru et al.}

Correspondence to: Laia Comas-Bru (1.comasbru@ reading.ac.uk)

The copyright of individual parts of the supplement might differ from the CC BY 4.0 License. 
Figure S1: Speleothem samples for the period 1958-2013 CE converted to their drip-water equivalent using the fractionation factors from Grossman and Ku (1986; black dots) and Tremaine Tremaine et al. (2011; red dots). We use simulated mean annual temperature (MAT) for the years when samples are available for the conversion. Vertical lines indicate the offset thresholds for 0.1 and $0.3 \%$ with the former corresponding to the average isotope uncertainty in the SISAL database. Maximum offset occurs at low MAT and is $0.86 \%$.

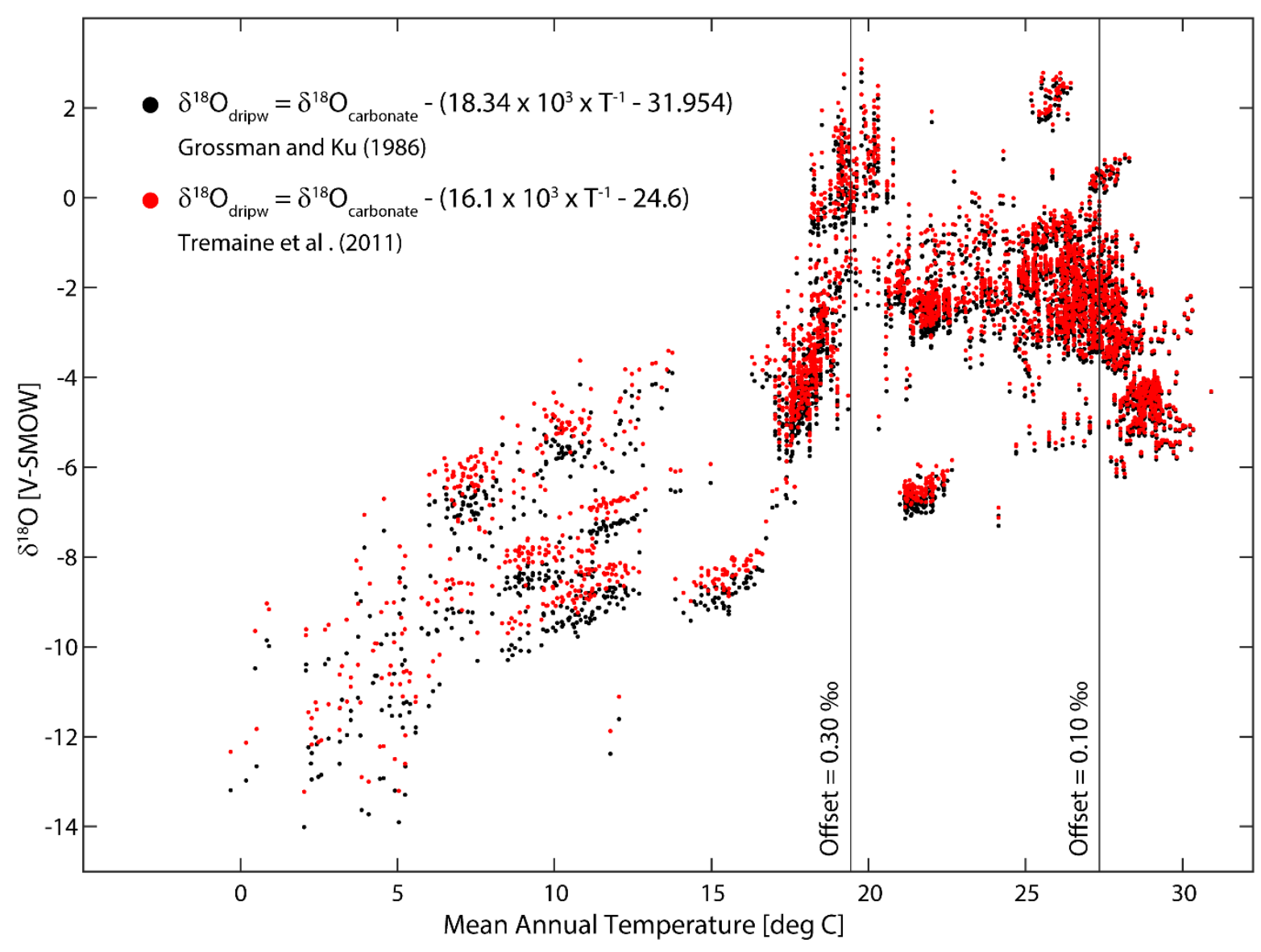


Figure S2: Data-model comparison for the modern period (1958-2013) using three methods to treat the simulated data: $(\mathbf{a}, \mathbf{b}) \delta^{18} \mathrm{O}$ in precipitation weighted according to the monthly precipitation amount. (c, d) $\delta^{18} \mathrm{O}$ in precipitation weighted according to the monthly potential infiltration calculated as precipitation $(P)$ minus evapotranspiration $(E)$ when $P-E>0$. $(e, f)$ soil water $\delta^{18} O$ weighted according to the monthly soil moisture content (i.e. soil water bucket). (a, c, e) show the data-model agreement. $(b, d, f)$ show the linear regressions of simulated $\delta^{18} O$ vs SISAL $\delta^{18} O$ data.

(a)

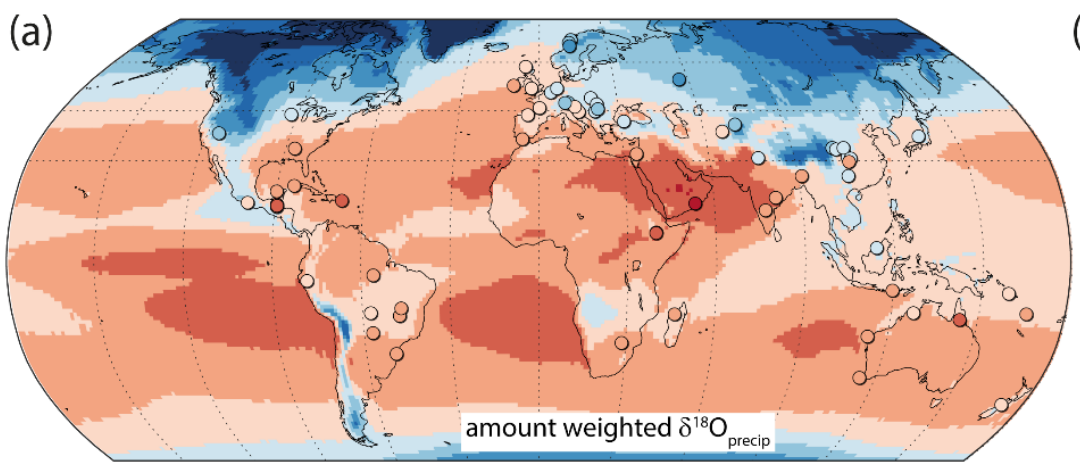

(c)

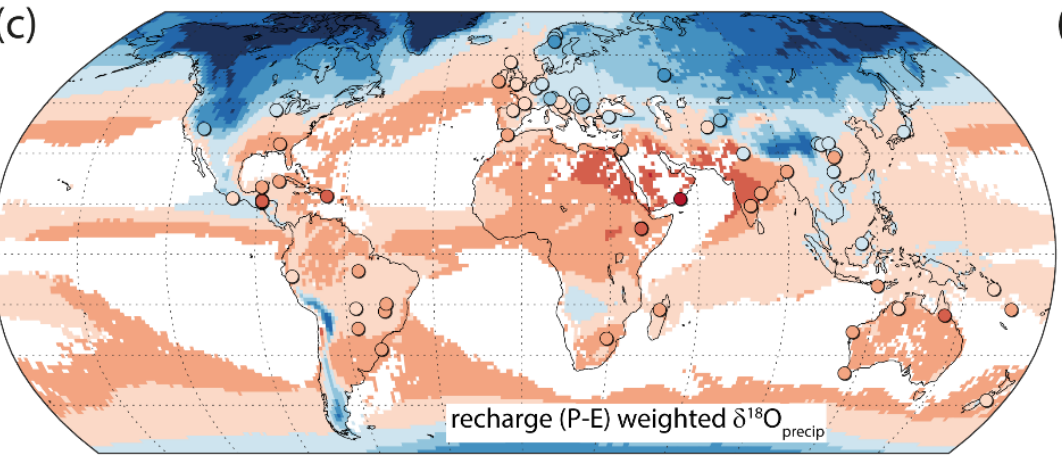

(e)

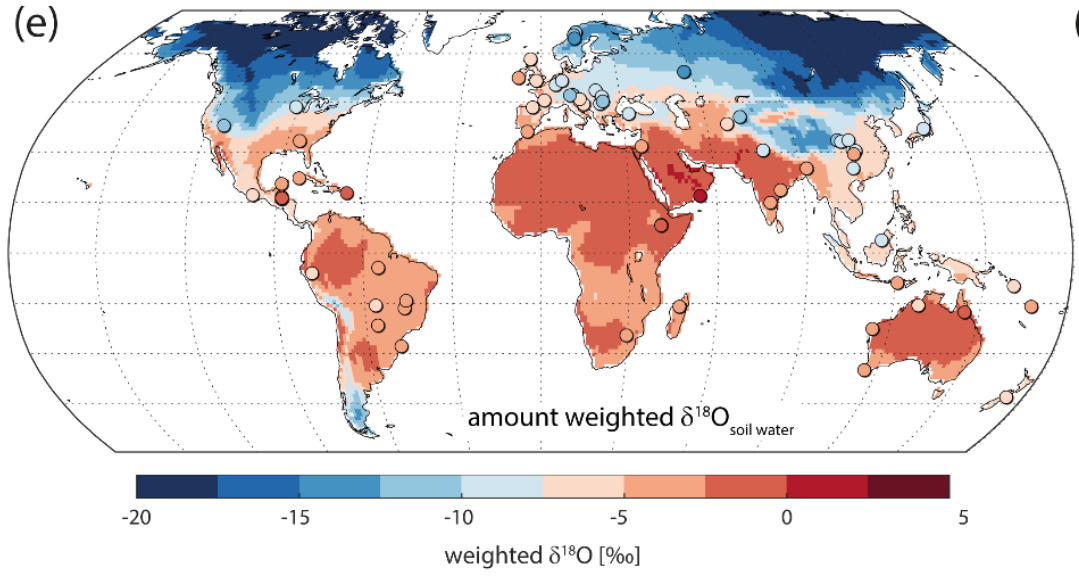

(b)

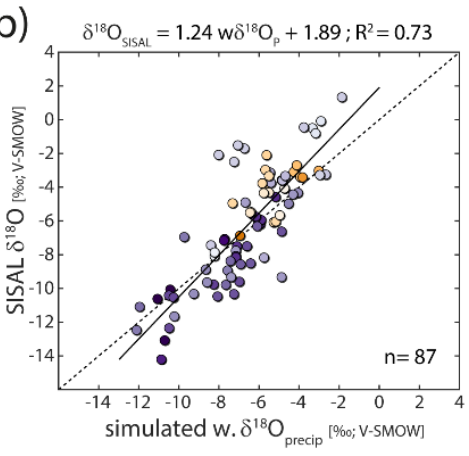

(d)

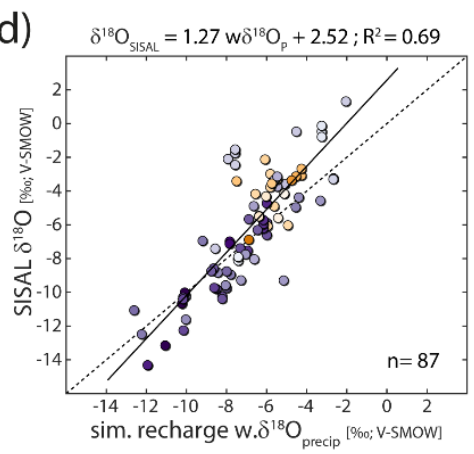

(f)

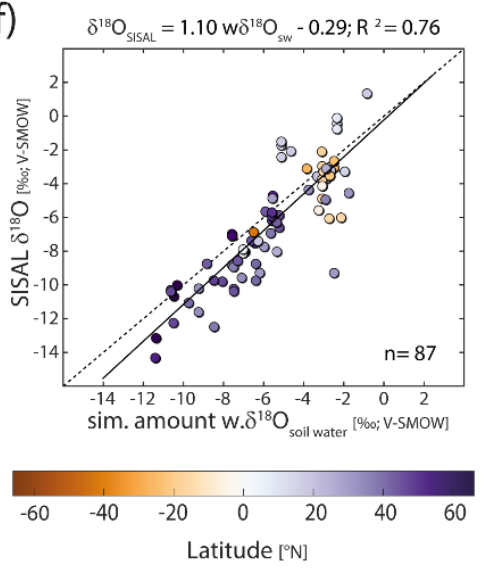


Figure S3: Linear regressions between SISAL $\delta^{18} \mathrm{O}$ and simulated amount-weighted $\delta^{18}$ Oprecip (top row), recharge weighted $\delta^{18} \mathrm{O}$ (middle row) and amount weighted $\delta^{18} \mathrm{Osw}$ for the period (1958-2013 CE). Data used in first column are long-term SISAL and ECHAM5-wiso data (as in Supplementary Figure 1). Second column is the regression on a year to year basis (i.e. using simulated data only for the years for which SISAL data is available). Third, fourth and fifth columns are the same as the latter after applying a smoothing of 5-10- and 15-yrs respectively. The smoothing was applied using the 5, 10 and 15 years previous to the SISAL's sample date and all years carried the same weight on the mean value. Solid black line is the regression line. Dashed grey line is the $1: 1$ line. Correlation coefficients $\left(R^{2}\right)$ are at the bottom right of each panel.
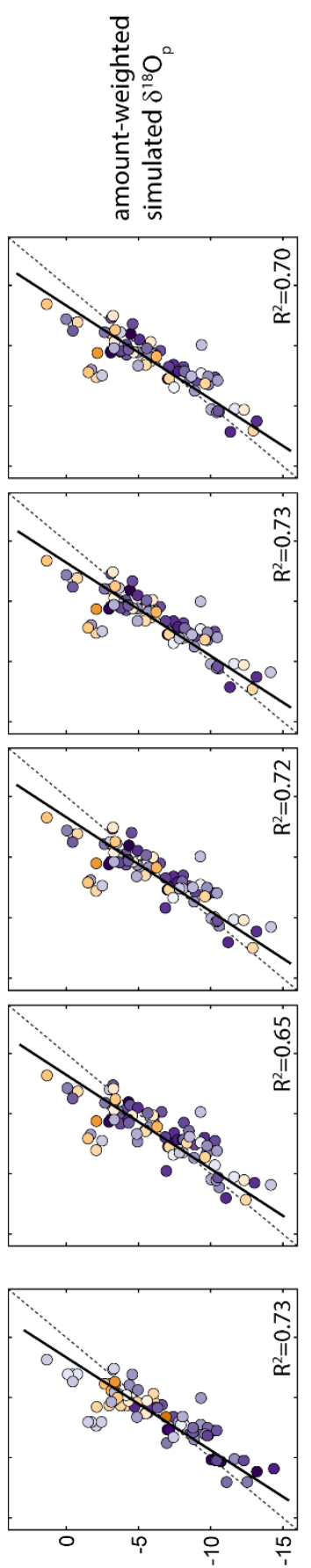

[MOWS $\wedge \%$ ] $\mathrm{O}_{81} \mathrm{Q}$ ] $\forall \mathrm{SIS}$
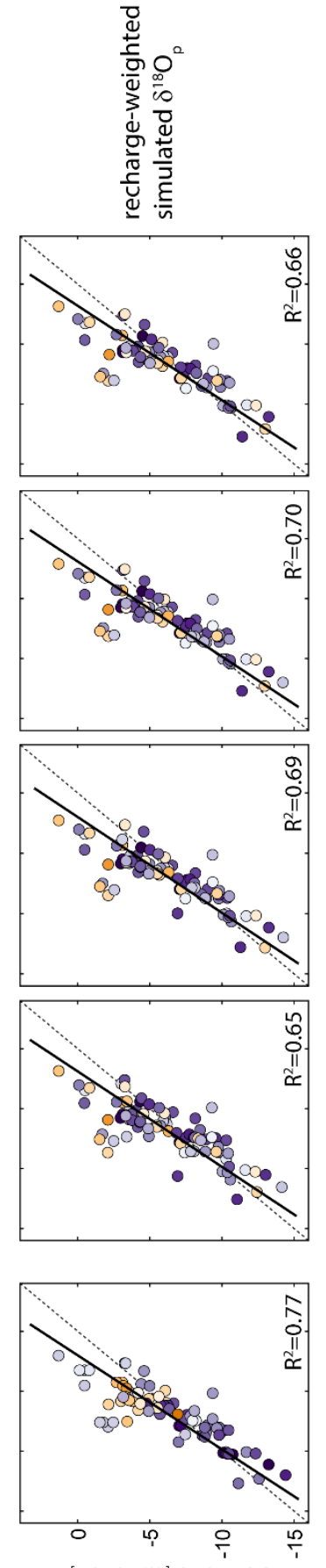

[MOWS $\wedge \%$ ] $\mathrm{O}_{81} \mathrm{Q}$ ] $\mathrm{SSIS}$
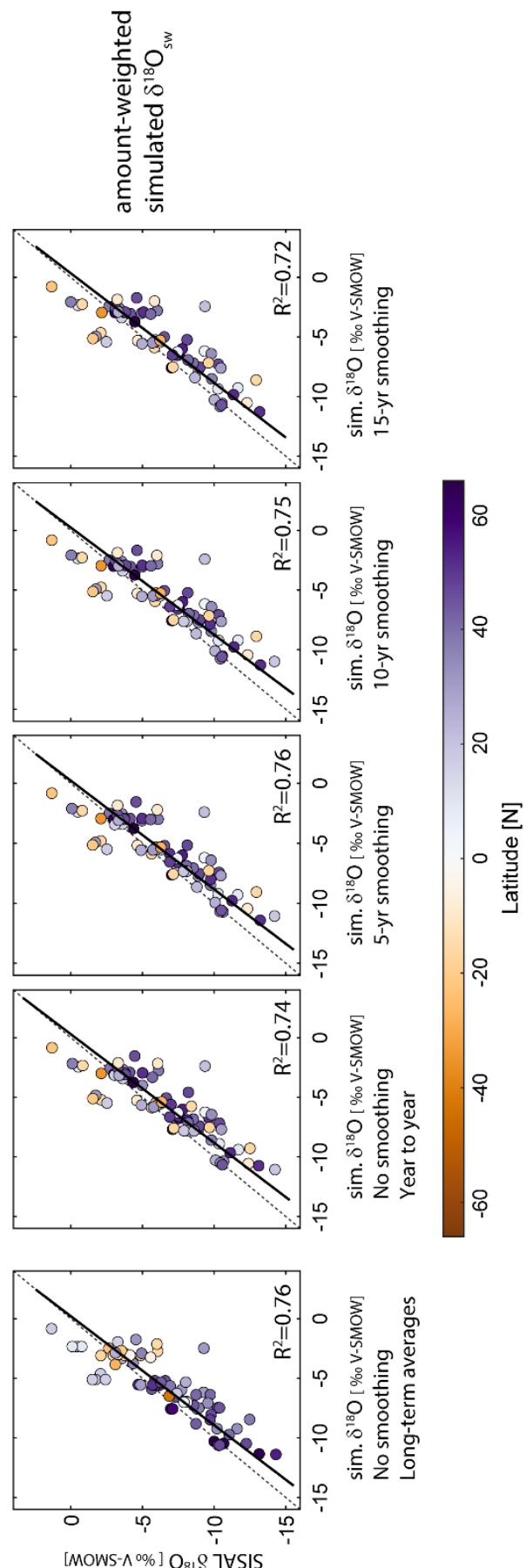
Figure S4: Linear regression between SISAL $\delta^{18} \mathrm{O}$ averages during the modern period (1961-1990 CE) and the pre-industrial $(1850 \pm 15 \mathrm{CE})$. Colour bar shows the difference between the two time periods in \%o V-PDB.

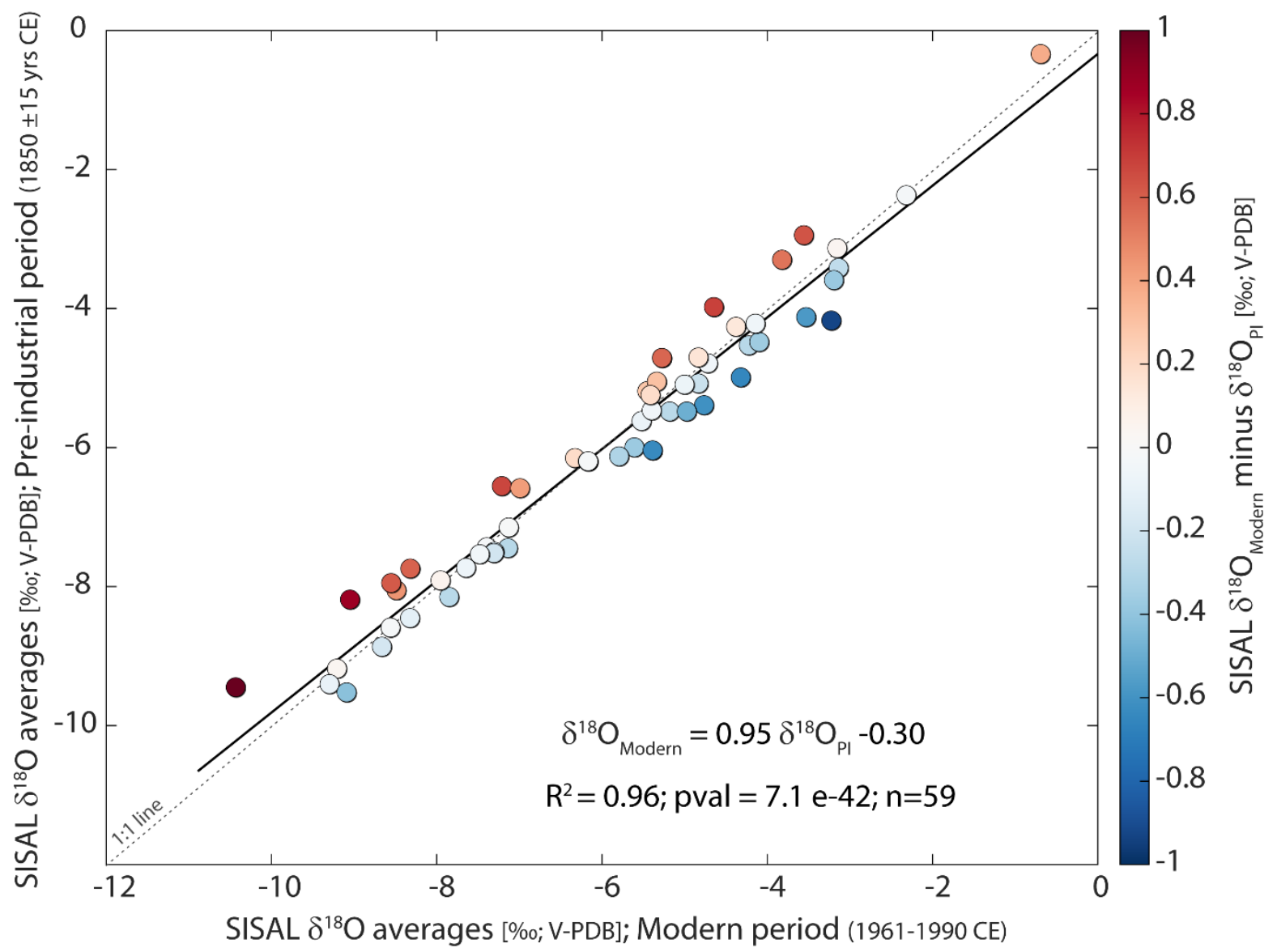


Figure S5: Impact of using time-windows shorter than the convention of \pm 500 yrs on SISAL MH-PI anomalies. (a) Boxplots of the global $\delta^{18} \mathrm{O} \mathrm{MH}-\mathrm{PI}$ anomalies across time window widths. (b) Anomalies using windows of 100 to 400 yrs versus the anomalies calculated using the conventional $500 \mathrm{yrs}$. (c) Differences between MH-PI anomalies using 500 and 100 yrs. See Supplementary Table 1 for the number of entities and sites available for each window width.

(a)

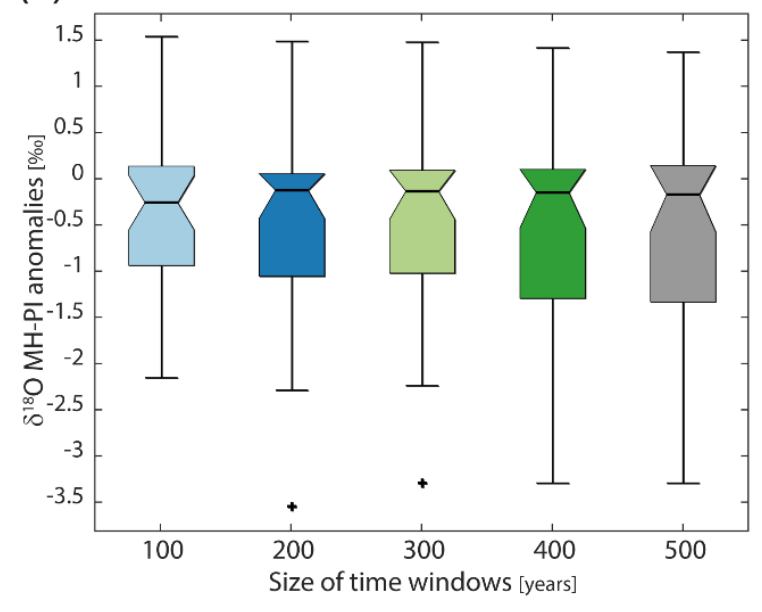

(b)

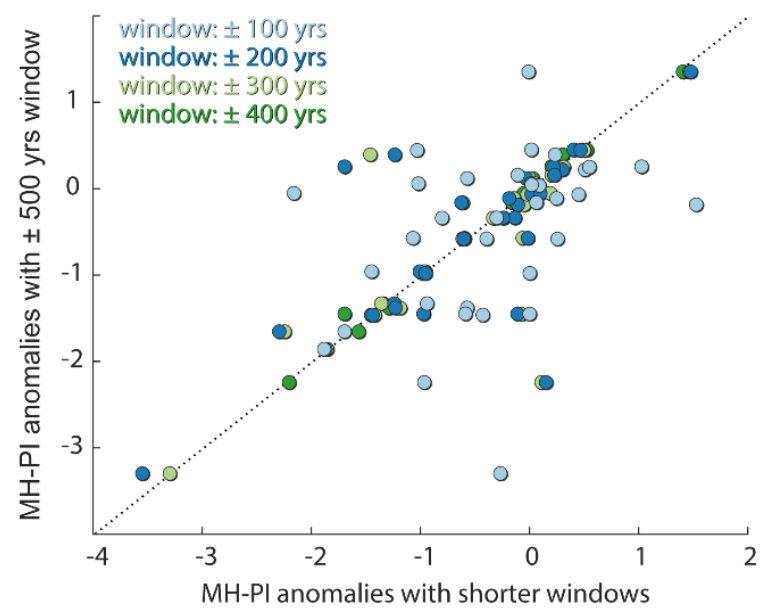

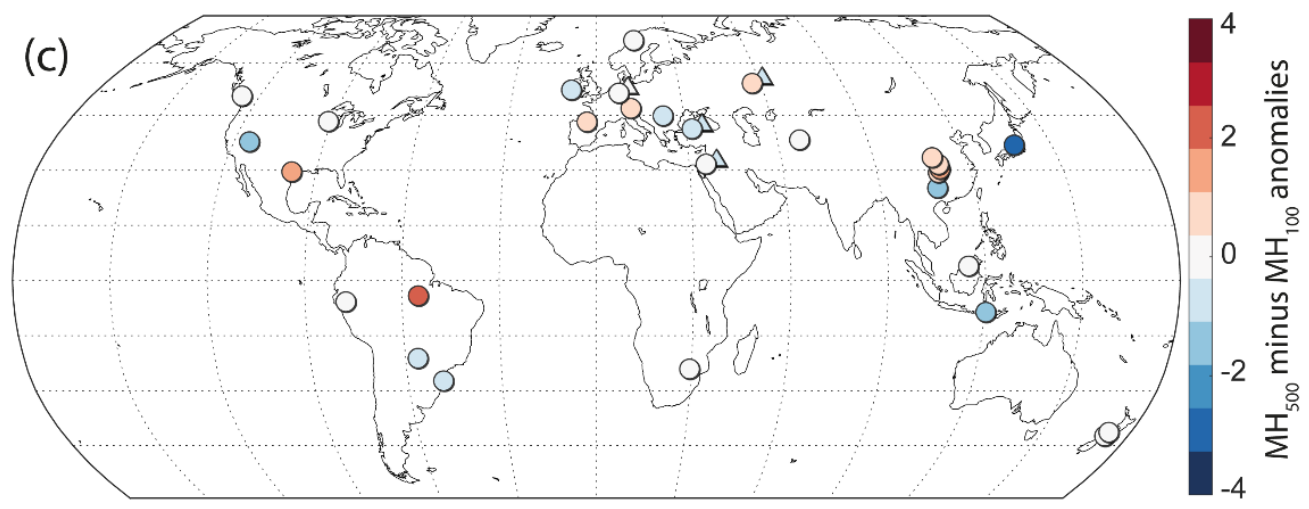


Figure S6: Impact of using time-windows shorter than the convention of $\pm 1,000 \mathrm{yrs}$ on SISAL LGM-PI anomalies. (a) Boxplots of the global $\delta^{18} \mathrm{O}$ LGM-PI anomalies across time window widths. (b) Anomalies using windows of 200 to 400 yrs versus the anomalies calculated using the conventional 1,000 yrs. (c) Differences between LGM-PI anomalies using 1,000 and 200 yrs. See Supplementary Table 2 for the number of entities and sites available for each window width.

(a)

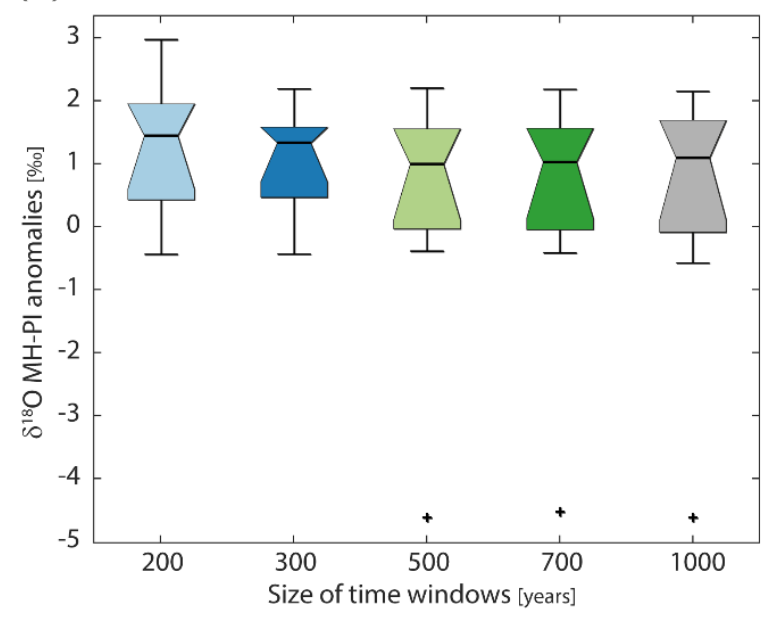

(b)

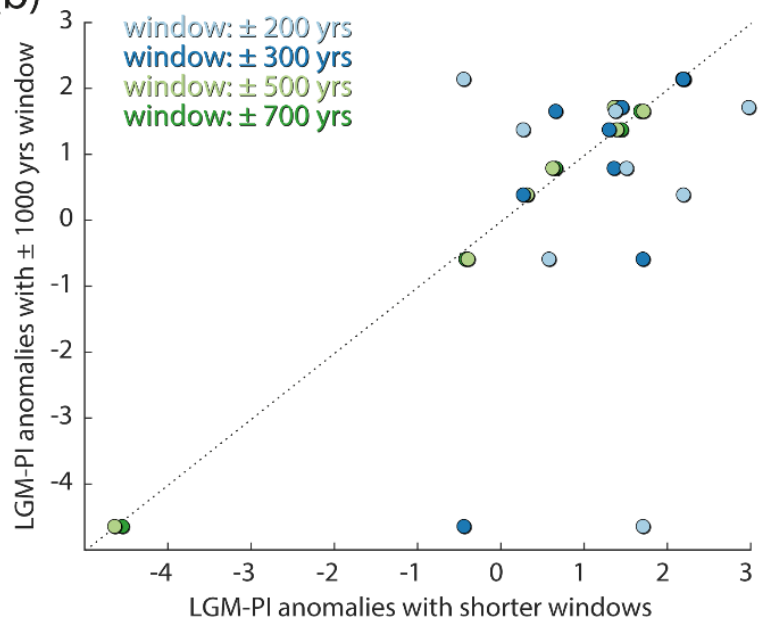

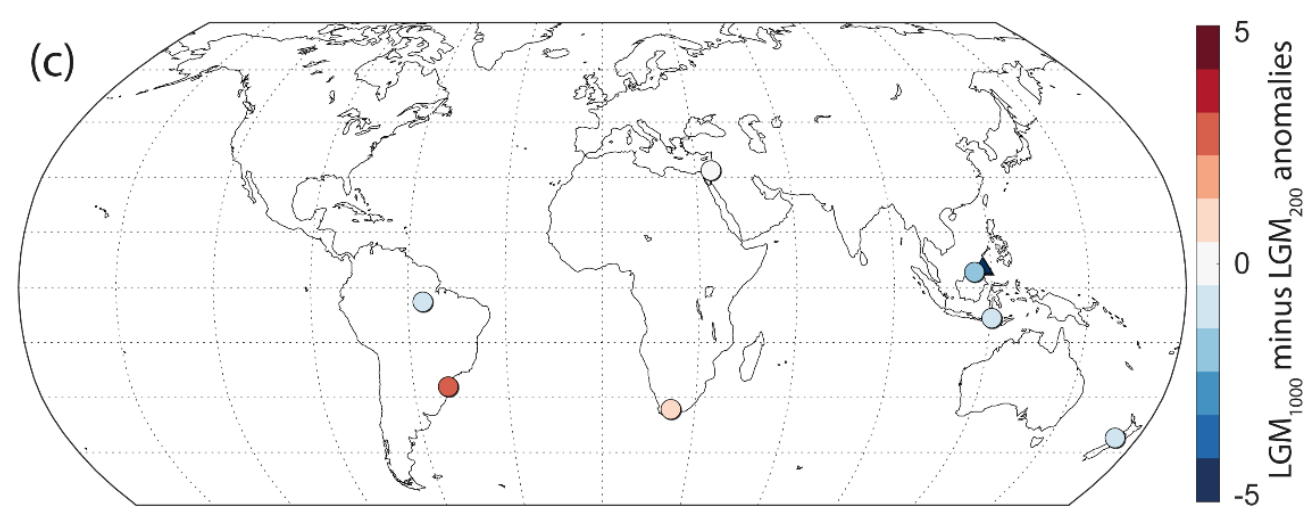


Table S1: Number of entities used in Figure S5.

\begin{tabular}{|l|l|l|l|l|}
\hline MH window size & Individual entities & Individual sites & $\begin{array}{l}\text { Individual entities } \\
\text { overlapping with } \\
\text { ext. PI }\end{array}$ & $\begin{array}{l}\text { Individual sites } \\
\text { overlapping with } \\
\text { ext. PI (1850- } \\
1990)\end{array}$ \\
\hline $\pm 500 \mathrm{yrs}$ & 106 & 74 & 36 & 32 \\
\hline $\pm 400 \mathrm{yrs}$ & 105 & 73 & 36 & 32 \\
\hline $\pm 300 \mathrm{yrs}$ & 104 & 73 & 35 & 32 \\
\hline $\pm 200 \mathrm{yrs}$ & 99 & 73 & 35 & 32 \\
\hline $\pm 100 \mathrm{yrs}$ & 92 & 68 & 33 & 30 \\
\hline
\end{tabular}

Table S2: Number of entities used in Figure S6.

\begin{tabular}{|l|l|l|l|l|}
\hline LGM window size & Individual entities & Individual sites & $\begin{array}{l}\text { Individual entities } \\
\text { overlapping with } \\
\text { ext. PI }\end{array}$ & $\begin{array}{l}\text { Individual sites } \\
\text { overlapping with } \\
\text { ext. PI }\end{array}$ \\
\hline \pm 1000 yrs & 48 & 35 & 11 & 10 \\
\hline \pm 700 yrs & 45 & 34 & 10 & 10 \\
\hline \pm 500 yrs & 43 & 33 & 10 & 10 \\
\hline \pm 300 yrs & 41 & 31 & 9 & 9 \\
\hline \pm 200 yrs & 39 & 29 & 8 & 8 \\
\hline
\end{tabular}

\section{Reference list}

Grossman, E. L., and Ku, T.-L.: Oxygen and carbon isotope fractionation in biogenic aragonite:

Temperature effects, Chemical Geology: Isotope Geoscience section, 59, 59-74, https://doi.org/10.1016/0168-9622(86)90057-6, 1986.

Tremaine, D. M., Froelich, P. N., and Wang, Y.: Speleothem calcite farmed in situ: Modern calibration of $\delta 180$ and $\delta 13 \mathrm{C}$ paleoclimate proxies in a continuously-monitored natural cave system, Geochimica et Cosmochimica Acta, 75, 4929-4950,

https://doi.org/10.1016/j.gca.2011.06.005, 2011. 